\title{
Acute Neurological Toxicity (NT) and Long-Term Outcomes in High-grade Glioma RTOG Trials
}

\author{
Y. R. Lawrence \\ M. Wang \\ Radiation Therapy Oncology Group
}

Thomas Jefferson University and Hospitals

\section{A. P. Dicker}

Thomas Jefferson University and Hospitals

D. W. Andrews

Thomas Jefferson University

\section{W. J. Curran} Follow University

Part of the Oncology Commons

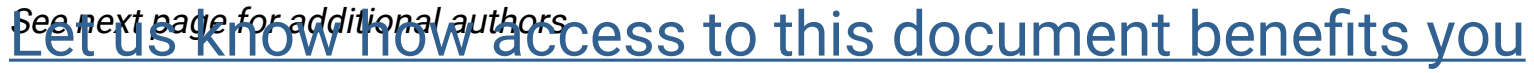

\section{Recommended Citation}

Lawrence, Y. R.; Wang, M.; Dicker, A. P.; Andrews, D. W.; Curran, W. J.; Michalski, J. M.; Souhami, L.; Yung, W. A.; and Mehta, M. (2010) "Acute Neurological Toxicity (NT) and Long-Term Outcomes in High-grade Glioma RTOG Trials," Bodine Journal: Vol. 3 : Iss. 1 , Article 6.

DOI: https://doi.org/10.29046/TBJ.003.1.005

Available at: https://jdc.jefferson.edu/bodinejournal/vol3/iss1/6

This Article is brought to you for free and open access by the Jefferson Digital Commons. The Jefferson Digital Commons is a service of Thomas Jefferson University's Center for Teaching and Learning (CTL). The Commons is a showcase for Jefferson books and journals, peer-reviewed scholarly publications, unique historical collections from the University archives, and teaching tools. The Jefferson Digital Commons allows researchers and interested readers anywhere in the world to learn about and keep up to date with Jefferson scholarship. This article has been accepted for inclusion in Bodine Journal by an authorized administrator of the Jefferson Digital Commons. For more information, please contact: JeffersonDigitalCommons@jefferson.edu. 


\section{Acute Neurological Toxicity (NT) and Long-Term Outcomes in High-grade Glioma}

RTOG Trials

\section{Authors}

Y. R. Lawrence, M. Wang, A. P. Dicker, D. W. Andrews, W. J. Curran, J. M. Michalski, L. Souhami, W. A. Yung, and M. Mehta 


\title{
Acute Neurological Toxicity (NT) and Long-Term Outcomes in High-grade Glioma RTOG Trials
}

\author{
Lawrence, Y.R., ${ }^{1}$ Wang, M., ${ }^{2}$ Dicker, A., ${ }^{1}$ Andrews, D.W., ${ }^{3}$ Curran, W.J., ${ }^{4}$ Michalski, J.M., ${ }^{5}$ Souhami, L., ${ }^{6}$ Yung, W.A., ${ }^{7}$ Mehta, M. \\ ${ }^{1}$ Department of Radiation Oncology, Thomas Jefferson University and Hospitals, Philadelphia, PA \\ 2Statistical Center, Radiation Therapy Oncology Group, Philadelphia, PA \\ ${ }^{3}$ Department of Neurological Surgery, Thomas Jefferson University, Philadelphia, PA \\ ${ }^{4}$ Emory University, Atlanta, GA \\ ${ }^{5}$ Washington University School of Medicine, St Louis, MO \\ ${ }^{6}$ Department of Radiation Oncology, McGill University Health Centre, Montreal, QC, Canada \\ `University of Texas M. D. Anderson Cancer Center, Houston, TX \\ \&University of Wisconsin Medical School, Madison, WI
}

\section{Background}

Treatment of high-grade glioma consists of fractionated radiation therapy $(\mathrm{RT}) \pm$ chemotherapy. The incidence/significance of neurological toxicity (NT) in this disease is not known. We evaluated the relationship between acute and chronic NT, and ultimate outcome, as well as risk factors for NT from the RTOG database.

\section{Methods}

Acute ( $\leq 90$ days of RT start) and late ( $>90$ days) NT events $\geq$ grade 3 were analyzed amongst 2,761 patients from 14 RTOG RT glioma studies, accrued from 1983-2003. Scoring schema used were RTOG Acute Morbidity Scoring Criteria, RTOG/EORTC Late Radiation Morbidity Scoring Schema and NCI-CTC version 2.0. The incidence of acute and late NT, the risk factors for these, correlation between acute and late NT, and eventual outcome were analyzed. Statistical methods included Chi squared test, McNemar's test, logistic regression, and Cox proportional hazards model. Two sided test was used, significance level 0.05 .

\section{Results}

Of 2,610 analyzable patients, $86 \%$ had glioblastoma, and $10 \%$ anaplastic astrocytoma. All received a systemic agent during RT (78\% BCNU, $5 \%$ thalidomide, $5 \%$ tirapazamine, $12 \%$ other agents). Median RT dose: 60 Gy. There were 182 acute and 83 late NT events. On univariate analysis age $>50$, poor performance status, more aggressive surgery, poor neurological function, poor mental function and twice daily RT were associated with increased acute NT. All these variables, except age, were also associated with acute NT on multivariate analysis. There was a statistically significant correlation between acute and chronic NT ( $p<0.0001)$. In a step-wise logistic regression model considering once daily RT, use of chemotherapy, total RT dose (BED) and acute NT, the occurrence of acute NT was significantly associated with late NT $(\mathrm{OR}=2.48 ; 95 \% \mathrm{CI}=1.2-5.0 ; \mathrm{p}$ $=0.01)$. The presence of acute NT $(\mathrm{HR}=1.43 ; 95 \% \mathrm{CI}[1.2,1.7] ; \mathrm{p}<$ 0.0001 ) was also found to predict poor overall survival, independent of RPA class (median survival 7.8 vs. 11.8 months).

\section{Conclusion}

Acute NT is significantly associated with both chronic NT and overall survival.

Supported by RTOG U10 CA21661 and CCOP U10 CA37422 grants from the NCI. This abstract's contents are the sole responsibility of the authors and do not necessarily represent the official views of the NCI. 